\title{
Solitaire Stentectomy Using a Stent-Retriever Technique in a Porcine Model
}

\author{
Andreas Simgen ${ }^{1} \cdot$ Michael Kettner ${ }^{1}$. Frida Juliane Webelsiep ${ }^{1} \cdot$ Toshiki Tomori $^{1}$ Ruben Mühl-Benninghaus ${ }^{1}$. \\ Umut Yilmaz ${ }^{1}$ Pervinder Bhogal ${ }^{3}$ Matthias W. Laschke ${ }^{2}$ Michael D. Menger ${ }^{2}$. Wolfgang Reith ${ }^{1}$. \\ Philipp Dietrich ${ }^{1}$
}

Received: 20 November 2019 / Accepted: 15 April 2020 / Published online: 18 May 2020

(c) The Author(s) 2020

\begin{abstract}
Purpose Mechanical thrombectomy using the Solitaire device has become a standard treatment of ischemic stroke due to large vessel occlusions. Inadvertent detachment is a feared complication, which is associated with poor clinical outcome. The aim of this experimental study was to assess in a porcine model the feasibility and effectiveness of rescuing detached Solitaire devices using different stent retrievers.

Methods Solitaire FR devices $(4 \times 15 / 20 \mathrm{~mm}$ and $6 \times 20 / 30 \mathrm{~mm})$ were placed in the axillary artery of pigs. By means of 3 different stent retrievers (Trevo ProVue; EmboTrap II revascularization device; 3D revascularization device) a total of 24 rescue maneuvers ( 8 per retriever) were performed by deploying the retrievers within the deployed Solitaire devices and trapping parts of the Solitaire within the microcatheter. Rescue rates, rescue time and complications were assessed.

Results Overall stentectomy of the Solitaire devices was successful in all cases (100\%). Time of rescue was comparable using the applied stent retrievers (Trevo ProVue; EmboTrap II revascularization device; 3D revascularization device). Complications, such as entrapment of the Solitaire-retriever complex at the intermediate catheter, Solitaire migration, vasospasm, perforation, or dissection were not observed.

Conclusion Stentectomy of inadvertently detached Solitaire devices using different stent retrievers is a feasible and effective method. Rescue rates and times with the Trevo ProVue, EmboTrap II and 3D revascularization device were comparable.
\end{abstract}

Keywords Animal model · Trevo - Solitaire - EmboTrap II Revascularization Device · 3D Revascularization Device

$\begin{array}{ll}\text { Abbreviations } \\ \text { BA } & \text { Basilar artery } \\ \text { CT } & \text { Computertomography } \\ \text { DSA } & \text { Digital subtraction angiography } \\ \text { GP } & \text { Glycoprotein } \\ \text { IC } & \text { Intermediate catheter } \\ \text { ICA } & \text { Internal carotid artery } \\ \text { MCA } & \text { Middle cerebral artery }\end{array}$

Andreas Simgen

andreassimgen@googlemail.com

1 Department of Neuroradiology, Saarland University Hospital, Kirrbergerstraße1, 66424 Homburg/Saar, Germany

2 Institute for Clinical \& Experimental Surgery, Saarland University Hospital, Homburg/Saar, Germany

3 Department of Interventional Neuroradiology, The Royal London Hospital, Whitechapel Road, London, E1 1BB, UK

\section{Introduction}

Since 2015, mechanical thrombectomy with retrievable stents has become a standard treatment of ischemic stroke due to large vessel occlusion with very good clinical outcome [1]. The Solitaire AB/FR device (Medtronic, Irvine, CA, USA) was the first fully retrievable and self-expanding intracranial stent available [2]. Initially, this device was designed for stent-assisted treatment of intracranial aneurysms [3]. In 2008, one of the first cases was described in the literature where a Solitaire was used to retrieve an intra-arterial thrombus [4]. Ever since, the Solitaire device passed through several revisions (Solitaire 2 and Solitaire Platinum), leading to the current 2019 version Solitaire X and is probably the most widely used stent-retriever in the world. Incidences of device-related complications have been reported in literature between $<1-13 \%$, especially inadvertent detachment is a feared complication when using the Solitaire device and is associated with a poor clinical outcome [5-17]. The literature on inadvertent detachments 
is sparse, more likely outdated and seems to be an issue of first generation Solitaire devices (AB/FR) since cases of new generation Solitaire devices (2/Platinum/X) have not been reported. Therefore, when confronted with an inadvertent detachment, stentectomy should be the desired strategy in affected patients. Many techniques, ranging from surgical extraction to a variety of different endovascular approaches (balloons, snares, alligator devices, stentbased or combined techniques) to rescue stents have been reported with variable results [10, 12-22].

The purpose of this study was to assess in a porcine model the feasibility and effectiveness of using different stent retrievers in a single retriever technique to rescue detached Solitaire devices.

\section{Material and Methods}

\section{Animal care}

The experiments were approved by the governmental animal protection committee and performed in accordance with the European legislation on the protection of animals (Directive 2010/63/EU) and the National Institute for Health (NIH) guidelines on the care and use of laboratory animals (NIH publication \#85-23 Rev. 1985). Experiments were performed in 2 female Swabian Hall pigs (body weight: 40-50 kg) as previously described in detail [23]. The animals had free access to tap water and daily standard food. In order to prevent dehydration a permanent saline infusion was administered. After the experiment the animals were killed with an intracardiac injection of T61 (0.12 mL/kg; MSD Animal Health, Schwabenheim an der Selz, Germany).

\section{Stent Retrievers}

Acquisition of micro-computed tomography (CT) images of the used stent retrievers was performed as previously described in detail [24].

The Solitaire FR $(4.0 \times 20 \mathrm{~mm})($ Medtronic) has a tubular design with a longitudinal slit, is closed-cell in design and constructed from laser cut nitinol. The 4-mm device used has 3 distal markers made of platinum and the 6-mm device has 4 . Both have one proximal marker made of platinum. Proximally it features an oval, sloping running end [3].

The Trevo ProVue $(4.0 \times 20 \mathrm{~mm}$; Stryker, Kalamazoo, MI, USA) is a closed tubular and closed-cell design that consists of a flexible tapered nitinol core wire with a tapered distal section. Distally the retriever holds three platinum markers. In addition, platinum wires are integrated into the stent struts [25].
The 3D revascularization device $(4.5 \times 26 \mathrm{~mm}$; Penumbra, Alameda, CA, USA) is made of nitinol and possesses a partially tubular design with a combination of open and closed cells. It has four chamber-like sections, each with one central marker made of platinum and one additional marker located at the proximal end of the device [26].

The EmboTrap II Revascularization Device $(5.0 \times 21 /$ $33 \mathrm{~mm}$; Cerenovus, Johnson and Johnson, New Brunswick, NJ, USA) comprises a two-layer nitinol structure. The inner structure is tubular designed with a high radial force and provides a flow channel. The outer structure consists of 3-5 basket-like sections depending on the length of the device. The distal end possesses a closed mesh, which serves as a protection zone. It has four distal gold markers of which one is a tip marker with a length of $4 \mathrm{~mm}$ and proximal it has two gold markers [27].

\section{Intervention}

Two neurointerventionalists (W. R. 23 years of interventional experience; A. S. 6 years of interventional experience) performed all the interventions, which were conducted under fluoroscopy by using a monoplane angiographic system (Ziehm Vision imaging, Nuremberg, Germany). The Ultravist 370 (iopromide; Bayer Schering Pharma, Berlin, Germany) was used as a contrast agent. Endovascular procedures were performed after an intravenous bolus injection of 5000 IU heparin (Braun, Melsungen, Germany) and $2 \mathrm{mg}$ nimodipine (Carinopharm $\mathrm{GmbH}$, Elze, Germany).

\section{Stent Implant Procedure (e.g. Solitaire)}

After surgical exposure of the right femoral artery a short $5 \mathrm{~F}$ sheath was inserted by means of direct puncture. Supported by a 0.035 -inch standard angled guide wire (Terumo, Tokyo, Japan) the sheath was replaced by a long 6F Neuron MAX sheath (Penumbra), which was placed in the proximal subclavian artery. Through the sheath a 6F SOFIA (Microvention) intermediate catheter (IC) was inserted. Navigated with a Traxcess 0.014-inch microwire (Microvention), target vessels (axillary arteries and their branches) were reached with either a Rebar-18 or Rebar-27 microcatheter (Medtronic, Irvine, California, USA), depending on the size of the Solitaire device. The microcatheter was then loaded with the detached Solitaire device. Prior to that, the Solitaire device was pulled to the proximal edge of the introducer sheath until the proximal platinum marker was visible. Detachment was manually achieved by bending and twisting the pusher wire bidirectional, representing a type $\mathrm{A}$ detachment like previously described [15]. Loading the detached Solitaire device into the microcatheter was achieved by using the stiff-end of a 0.018-inch Muso-Wire (Terumo, 
a

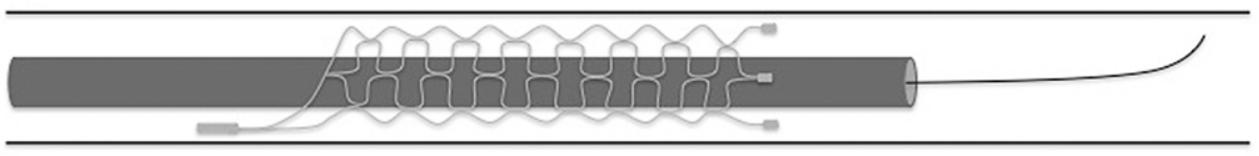

b

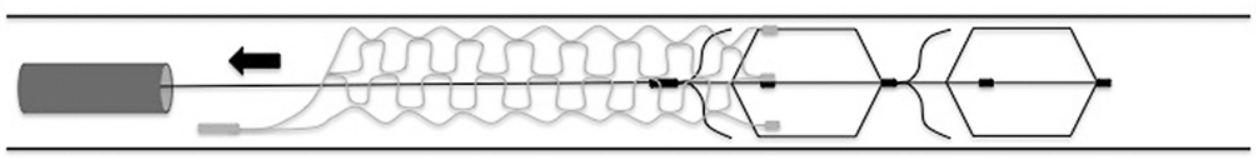

C

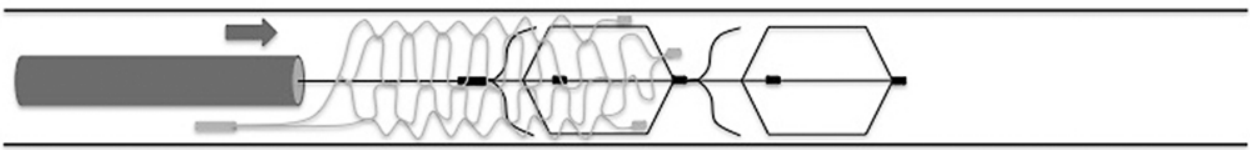

d

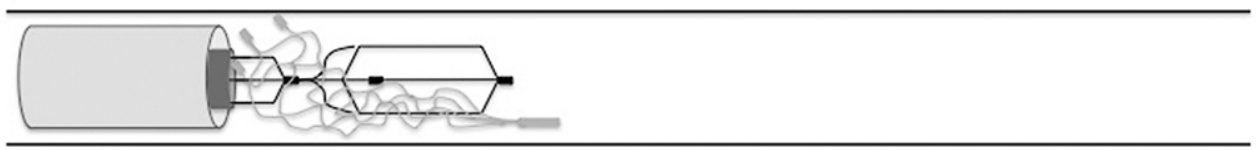

Fig. 1 Illustration of the stent-retriever technique with trapping of the detached Solitaire device. First the detached Solitaire device is passed with the microwire and microcatheter (a). Then the stent retriever is positioned two thirds distal of the detached Solitaire and one third within the Solitaire (b). After that the stent retriever is slowly pulled back until a change in configuration of the Solitaire is noted (c). Subsequently, resheathment of the stent retriever is achieved by gently advancing the microcatheter until a mild resistance is felt at the pusher wire of the stent retriever, indicating that the Solitaire is trapped. Following this and under continuous tension of the pusher wire, the complete Solitaire-retriever complex is pulled inside of the IC (d)

Tokyo, Japan). Deployment of the detached Solitaire devices was achieved by gently pushing the Muso-Wire while simultaneously retracting the microcatheter until the Solitaire device was fully unfolded.

\section{Stentectomy Procedure}

Once the Solitaire device was deployed different microcatheters, depending on the stent retriever, were navigated through the Solitaire using a J-shaped Traxcess 0.014-inch microwire (Microvention). The Trevo ProVue was positioned using a Trevo-18 microcatheter (Stryker), the EmboTrap II using a Rebar-18 microcatheter (Medtronic) and the $3 \mathrm{D}$ revascularization device using a 0.025 -inch Velocity microcatheter (Penumbra). In each maneuver the stent retriever was positioned two thirds distal of the detached Solitaire and one third within the Solitaire so that the distal end of the Solitaire was completely covered. After that the stent retriever was slowly pulled back until a change in configuration of the Solitaire was noted. Subsequently the stent retriever was resheathed by gently advancing the microcatheter until a mild resistance was felt at the pusher wire of the stent retriever, indicating that the Solitaire was trapped. Following this and under continuous tension of the pusher wire, the complete Solitaire-retriever complex was extracted (Fig. 1a-d and Fig. 2a-f). This technique has previously been described to retrieve migrated coils $[23,28$, 29].

\section{Angiographic Evaluation}

With each stent retriever 8 detached Solitaire devices at various vessel positions were performed. Rescue was considered successful if the Solitaire device was extracted from the animal. If it was not possible to rescue the Solitaire device, the attempt was declared as having failed. After each rescue maneuver, digital subtraction angiography (DSA) was performed to evaluate vessel complications. The following parameters were assessed:

1. Rescue rates for each clot retriever

2. Rescue time, defined as time between navigation through the Solitaire and successful extraction.

3. Complications: vasospasm, perforation, dissection, entrapment at intermediate catheter, inadvertent deployment and migration of the Solitaire.

\section{Statistical Analysis}

Continuous variables are expressed as means and standard deviations. Continuous variables were tested for normal distribution. Rescue times between the different stent retrievers (TREVO ProVue versus EmboTrap; TREVO ProVue versus 3D Revascularization Device; EmboTrap versus 3D Revascularization Device) were compared by one-way ANOVA followed by post hoc analysis including correction of the $\alpha$ error according to Bonferroni. Statistical significance was 

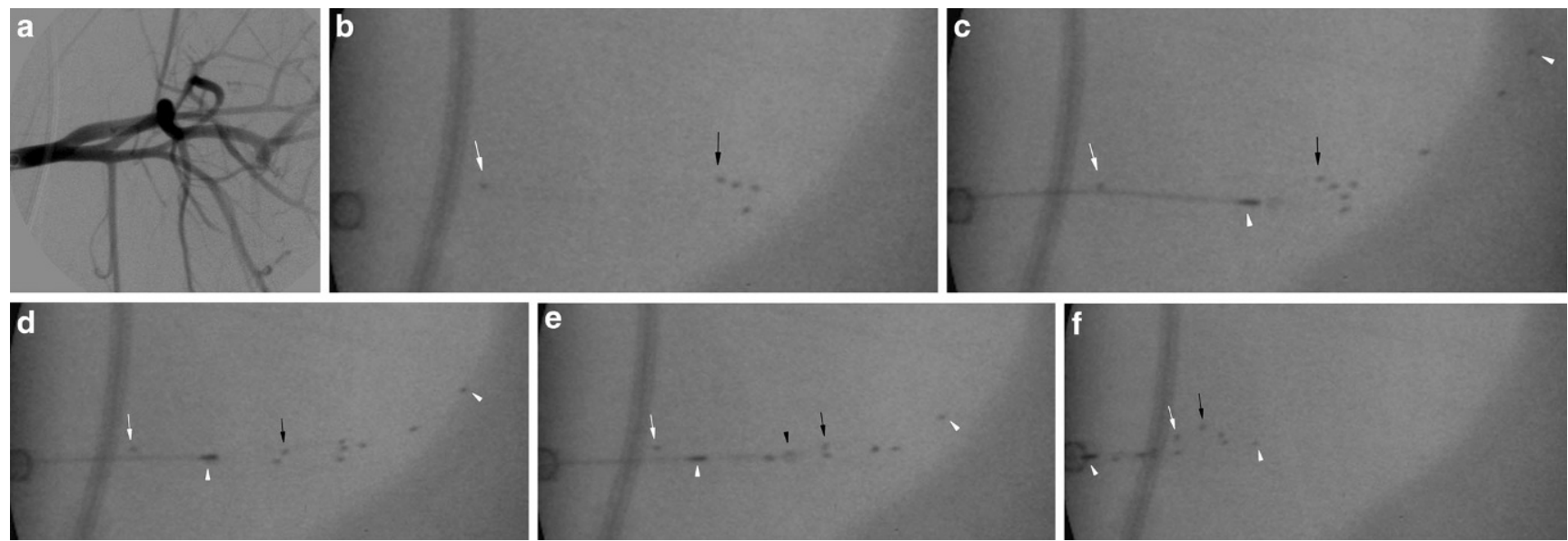

Fig. 2 a DSA of the left subclavian artery, axillary arteries and its branches. b Fluoroscopy image of the detached Solitaire FR $6 \times 20 \mathrm{~mm}$. The white arrow indicates the proximal marker and the black arrow the 4 distal markers. c Deployment of the 3D Revascularization Device (arrowheads indicate the proximal and distal marker) within the distal two thirds of the Solitaire FR. d Retraction of the 3D Revascularization Device with notable change in configuration of the distal markers of the Solitaire FR (black arrow). e Resheathment of the 3D Revascularization Device by advancing the microcatheter until entrapment of the Solitaire FR (black arrowhead indicates the tip of the microcatheter). $\mathbf{f}$ Partial retraction of the 3D Revascularization Device and trapped Solitaire FR within the IC

accepted at a two-sided $p$ value of $<0.05$. All data analyses were performed using SPSS Statistics 22 (IBM, Chicago, IL, USA).

\section{Results}

\section{Vessel and Solitaire Sizes}

Using the aforementioned stent retrievers a total of 24 rescue maneuvers were performed in 2 pigs (12 in each pig). With each stent retriever (Trevo ProVue; EmboTrap II; 3D Revascularization Device) a total of 8 rescue maneuvers was performed. For this purpose, the target vessels were the axillary arteries with a mean diameter of $3.38 \pm 0.74 \mathrm{~mm}$ (animal 1) and $3.29 \pm 0.79 \mathrm{~mm}$ (animal 2). We implanted a total of 24 Solitaire FR devices of different sizes $(4 \times 15 \mathrm{~mm} n=4,4 \times 20 \mathrm{~mm} n=8,6 \times 20 \mathrm{~mm} n=4$ and $6 \times 30 \mathrm{~mm} n=8)$.

\section{Rescue Rate and Time}

Successful rescue was achieved in all 24 cases, corresponding to a rescue rate of $100 \%$. The results of the different stent retrievers are listed in detail in Table 1. Using each stent retriever (Trevo ProVue; EmboTrap II; 3D Revascularization Device) we achieved a rescue time of $1-3 \mathrm{~min}$. Comparison of the rescue times of the stent retrievers revealed no statistical significant differences (TREVO ProVue versus EmboTrap, $p=0.316$; TREVO ProVue versus 3D Revascularization Device, $p=0.350$; EmboTrap versus 3D Revascularization Device, $p=0.122$ ) (Table 1). When pulling the Solitaire-retriever complex inside the IC only a mild resistance was felt. We did not observe a failed rescue. Passage of the Solitaire devices with the microwire and microcatheter was mostly possible at the first attempt using a Jshaped tip on the microwire. The shape of the microwire had to be adjusted in order to achieve the passage only in a few cases.

Table 1 Overview of results comparing the applied clot retrievers

\begin{tabular}{lllllllll}
\hline Devices & $\begin{array}{l}\text { Rescue } \\
\text { rate }(\%)\end{array}$ & $\begin{array}{l}\text { Time of } \\
\text { rescue }(\mathrm{s})\end{array}$ & $\begin{array}{l}\text { Vasospasm } \\
(n)\end{array}$ & $\begin{array}{l}\text { Perforation } \\
(n)\end{array}$ & $\begin{array}{l}\text { Dissection } \\
(n)\end{array}$ & $\begin{array}{l}\text { Entrapment at } \\
\text { IC }(n)\end{array}$ & $\begin{array}{l}\text { Inadvertent de- } \\
\text { tachment }(n)\end{array}$ & $\begin{array}{l}\text { Solitaire migra- } \\
\text { tion }(n)\end{array}$ \\
\hline $\begin{array}{l}\text { Trevo } \\
\text { ProVue }\end{array}$ & 100 & $118.85 \pm 14.59$ & 0 & 0 & 0 & 0 & 0 & 0 \\
EmboTrap II 100 & $110.14 \pm 16.51$ & 0 & 0 & 0 & 0 & 0 & 0 \\
3D & 100 & $130.29 \pm 27.45$ & 0 & 0 & 0 & 0 & 0 & 0 \\
\hline
\end{tabular}

$I C$ intermediate catheter

$p=0.316$ TREVO ProVue versus EmboTrap

$p=0.350$ TREVO ProVue versus 3D Revascularization Device

$p=0.122$ EmboTrap versus 3D Revascularization Device 


\section{Complications}

We did not observe any cases of vasospasm, perforation or dissection. Neither entrapment of the Solitaire-retriever complex at the intermediate catheter nor migration of the Solitaire devices during navigating was observed.

\section{Micro-CT of the Rescued Solitaire Devices}

The rescued Solitaire devices were assessed using microCT. The images revealed a distinct deformation of each Solitaire device. The point of entrapment was mostly identified directly at one of the distal radiopaque markers, were an abnormal bending of the devices was noted (Fig. 3a). Furthermore, all Solitaire devices were heavily invaginated so that the original open tubular design was no longer recognizable (Fig. 3b).
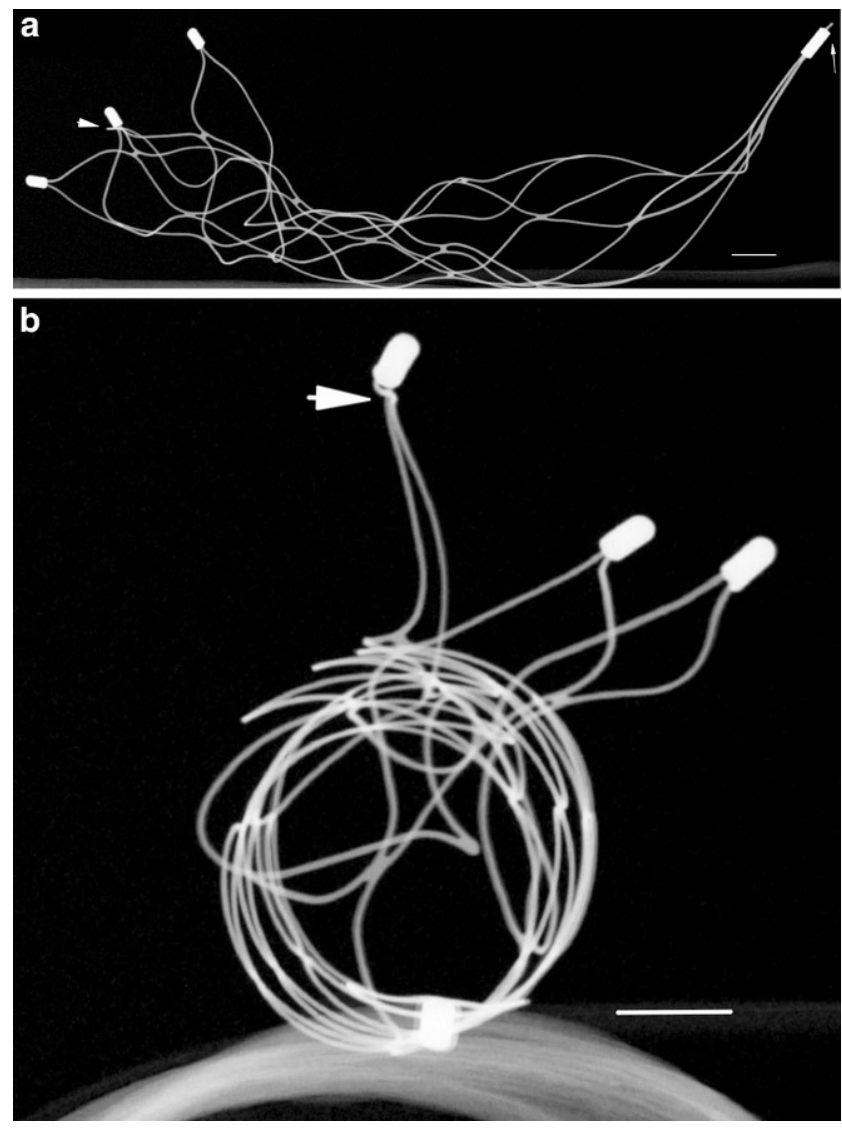

Fig. 3 Micro-CT 3D-reconstruction of a rescued Solitaire FR transversal and longitudinal (a and $\mathbf{b}$ ), revealing a distinct deformation and invagination. The thick arrow indicates one of the trapped distal markers and shows an abnormal bending. The thin arrow indicates the detachment zone presenting as a type A detachment. Scale bar $=1 \mathrm{~mm}$

\section{Discussion}

Inadvertent detachment of the Solitaire device during thrombectomy is a rare complication, but is associated with poor clinical outcome and even increased mortality $[15,16,30]$. Reports in the literature were more frequently published in the early years of mechanical thrombectomy with use of the first generation Solitaire devices (AB/FR) $[17,30]$. To date, unexpected detachment of new generation devices (Solitaire 2/Platinum/X) have not been described. Nevertheless, the literature on this topic remains very sparse and most likely outdated. Intracranial arteriosclerotic disease and tortuous vessel anatomy as well as a high number of retrieval attempts seem to contribute to the risk of an unexpected detachment $[10,17]$. An in vitro study revealed that detachment most commonly occurs in or around the proximal marker [31]. In a clinical study Castano et al. were able to classify the seen detachments in two types, proximal (type A) and distal (type B) of the proximal marker [15].

To date, data on the management of inadvertent detached Solitaire devices are still limited and no standard protocol has been established. When confronted with such a case, a risk-benefit assessment should be carried out in order to decide between a conservative strategy or a stentectomy. Conservative strategies nowadays include administration of GP IIa/IIIb inhibitors followed by dual antiplatelet therapy and can be potentially catastrophic in ischemic stroke with an increased risk of intracranial hemorrhage [32]. When performing an endovascular stentectomy the extent of neointimal damage to the vessel remains uncertain. Furthermore, complications, such as vessel rupture or dissection must be taken into consideration when using such a procedure.

Many stentectomy techniques have been described in the literature, including the use of balloons [20], snares [19, 21], alligator devices [19] and the merci retriever system [18]. Stent-based techniques using stent retrievers, such as deploy and engage [16] have also been reported and demonstrated promising results. A potential major limitation of the deploy and engage technique might be a weak fixation of the detached stent during rescue [15]. Therefore, another interesting stent-based technique has been described called snare over stent-retriever (SOS) by Chapot et al. and Meyers et al. [22, 33]. With this combined technique the stentretriever is used to grasp and taper the proximal end of the detached stent so that the snare, which was initially slipped over the microcatheter of the stent-retriever, can be advanced and catch the proximal end of the detached stent. This technique showed promising results with high rescue rates in clinical and experimental reports mainly of stents used for stent-assisted coiling [22, 33]. 
Detached Solitaire devices were successfully rescued by sole use of a snare as long as the proximal markers were still visualized and not in contact with the vessel wall [15]. Another interesting approach described by Parthasarathy et al. [16] is the loop and snare technique, in which a microwire is looped inside the detached stent and advanced through the mesh back into the parent vessel. With another microcatheter a snare is advanced to catch the microwire so that the stent can be rescued.

In summary rescue maneuvers of Solitaire devices have been described in the literature using sole snares [15], stent retrievers (deploy and engage technique) and loop and snare technique [16].

The aim of the present study was to assess the feasibility and effectiveness of rescuing detached Solitaire devices using different stent retrievers in a porcine model. We chose this animal model because it has already been proven in several studies for the evaluation of endovascular complication management [23, 29]. Despite the very well developed silicone models, they cannot replace the animal model [34]. The applied stent retriever technique has already shown promising results in retrieving migrated coils in many studies using the Trevo ProVue [29] and 3D-Separator [23]. To our knowledge this technique has not been described to rescue detached Solitaire devices. Furthermore, rescue maneuvers using the EmboTrap II Revascularization Device have also not been described in literature.

The results show that overall rescues of detached Solitaire devices of different sizes were successful in 100\% (24 of 24 cases). Interestingly, rescue times were not significantly different when comparing the applied stent retrievers. We did not observe any case of entrapment of the Solitaireclot retriever complex at the intermediate catheter, Solitaire migration, vasospasm, perforation, or dissection.

Presumably the open tubular design of the Solitaire device is most likely the reason for the atraumatic rescue observed in our study. The design allows the Solitaire to be very flexible, which led to an extreme deformation of some devices during the rescue maneuvers. Due to the observed Solitaire deformations we would not recommend this rescue technique for other closed tubular stents.

Taken together, our study reveals that stentectomy of detached Solitaire devices with the applied stent retrievers is a fast and straightforward technique with a manageable risk profile. Compared to the above described techniques using more than one device, the deploy and engage technique or even dedicated rescue devices (snare and alligator), we believe that this technique is simpler, because it is closest to the regular use of a stent retriever in the setting of ischemic stroke. With the growing and more frequent treatment of ischemic stroke using stent retrievers, we believe that neurointerventionalists could benefit from this technique when confronted with an unexpected Solitaire detachment. Thus, we would consider the use of one of the applied stent retrievers as the first choice of therapy in the event of an inadvertent Solitaire detachment.

\section{Limitations}

In the porcine model used, stentectomy of detached Solitaires was performed in vessels representing the sizes of the MCA (M1 and M2 segment), BA and ICA in humans; however, human vessel anatomy is much more challenging in terms of tortuosity. A major limitation was that the detached Solitaire devices were rescued in patent and healthy vessels. In a human setting the stent to be rescued is most likely in an occluded, arteriosclerotically altered vessel with an elongated access path, so navigation is expected to be more challenging than in the animal model used. Furthermore, we were only able to rescue type A detachments of the Solitaire devices, but we do not see any reason why the described technique should not work for type B detachments. Only a small number of rescue maneuvers could be performed for each stent retriever since the supply of Solitaire devices for experimental use was limited.

\section{Conclusion}

This experimental study demonstrates that stentectomy of detached Solitaire devices using stent retrievers is a feasible and effective approach. Rescue rates and rescue times were comparable between the Trevo ProVue, EmboTrap II Revascularization Device and 3D Revascularization Device.

Acknowledgements We would like to thank the team of the Institute for Clinical \& Experimental Surgery, Saarland University, for supporting this study.

Funding This research received no specific grant from any funding agency in the public, commercial or not-for-profit sectors.

Author Contribution A. Simgen: Project development, interventions, angiographic evaluation and manuscript writing; M. Kettner: Interventions, angiographic evaluation; F. J. Webelsiep: Animal care, angiographic evaluation, editing; T. Tomori: Animal care, review editing; R. Mühl-Benninghaus: CT scanning; U. Yilmaz: statistical analysis; P. Bhogal: Review and editing; M. W. Laschke: Animal care and manuscript writing; M. D. Menger: Project development, review and editing; W. Reith: Project development, interventions, angiographic evaluation, review and editing; P. Dietrich: Interventions, angiographic evaluation and manuscript writing

Funding Open Access funding provided by Projekt DEAL.

\section{Compliance with ethical guidelines}

Conflict of interest A. Simgen, M. Kettner, F. J. Webelsiep, T. Tomori, R. Mühl-Benninghaus, U. Yilmaz, P. Bhogal, M. W. Laschke, M. D. Menger, W. Reith and P. Dietrich declare that they have no competing interests. 
Ethical standards The experiments were approved by the governmental animal protection committee and conducted in accordance with the European legislation on the protection of animals (Directive 2010/63/EU) and the NIH guidelines on the care and use of laboratory animals (NIH publication \#85-23 Rev. 1985).

Open Access This article is licensed under a Creative Commons Attribution 4.0 International License, which permits use, sharing, adaptation, distribution and reproduction in any medium or format, as long as you give appropriate credit to the original author(s) and the source, provide a link to the Creative Commons licence, and indicate if changes were made. The images or other third party material in this article are included in the article's Creative Commons licence, unless indicated otherwise in a credit line to the material. If material is not included in the article's Creative Commons licence and your intended use is not permitted by statutory regulation or exceeds the permitted use, you will need to obtain permission directly from the copyright holder. To view a copy of this licence, visit http://creativecommons.org/licenses/by/4. $0 /$.

\section{References}

1. Goyal M, Menon BK, van Zwam WH, Dippel DW, Mitchell PJ, Demchuk AM, Dávalos A, Majoie CB, van der Lugt A, de Miquel MA, Donnan GA, Roos YB, Bonafe A, Jahan R, Diener HC, van den Berg LA, Levy EI, Berkhemer OA, Pereira VM, Rempel J, Millán M, Davis SM, Roy D, Thornton J, Román LS, Ribó M, Beumer D, Stouch B, Brown S, Campbell BC, van Oostenbrugge RJ, Saver JL, Hill MD, Jovin TG; HERMES collaborators. Endovascular thrombectomy after large-vessel ischaemic stroke: a meta-analysis of individual patient data from five randomised trials. Lancet. 2016;387:1723-31.

2. Henkes H, Flesser A, Brew S, Miloslavski E, Doerfler A, Felber S, Monstadt H, Kuehne D. A novel microcatheter-delivered, highlyflexible and fully-retrievable stent, specifically designed for Intracranial use: technical note. Interv Neuroradiol. 2003;20:391-3.

3. Liebig T, Henkes H, Reinartz J, Miloslavski E, Kühne D. A novel self-expanding fully retrievable intracranial stent (SOLO): Experience in nine procedures of stent-assisted aneurysm coil occlusion. Neuroradiology. 2006;48:471-8.

4. Castaño C, Serena J, Dávalos A. Use of the new solitaire (TM) $\mathrm{AB}$ device for mechanical thrombectomy when merci clot retriever has failed to remove the clot. A case report. Interv Neuroradiol. 2009;15:209-14.

5. Nayak S, Ladurner G, Killer M. Treatment of acute middle cerebral artery occlusion with a Solitaire $\mathrm{AB}$ stent: preliminary experience. Br J Radiol. 2010;83:1017-22.

6. Miteff F, Faulder KC, Goh ACC, Steinfort BS, Sue C, Harrington TJ. Mechanical thrombectomy with a self-expanding retrievable intracranial stent (Solitaire $\mathrm{AB}$ ): experience in 26 patients with acute cerebral artery occlusion. AJNR Am J Neuroradiol. 2011;32:1078-81.

7. Dorn F, Stehle S, Lockau H, Zimmer C, Liebig T. Endovascular treatment of acute intracerebral artery occlusions with the solitaire stent: single-centre experience with 108 recanalization procedures. Cerebrovasc Dis. 2012;34:70-7.

8. Saver JL, Jahan R, Levy EI, Jovin TG, Baxter B, Nogueira RG, Clark W, Budzik R, Zaidat OO; SWIFT Trialists. Solitaire flow restoration device versus the Merci Retriever in patients with acute ischaemic stroke (SWIFT): a randomised, parallel-group, non-inferiority trial. Lancet. 2012;380:1241-9.

9. Pereira VM, Gralla J, Davalos A, Bonafé A, Castaño C, Chapot R, Liebeskind DS, Nogueira RG, Arnold M, Sztajzel R, Liebig T, Goyal M, Besselmann M, Moreno A, Schroth G. Prospective, multicenter, single-arm study of mechanical thrombectomy us- ing Solitaire Flow Restoration in acute ischemic stroke. Stroke. 2013;44:2802-7.

10. Kang DH, Park J, Hwang YH, Kim YS. Inadvertent self-detachment of Solitaire $\mathrm{AB}$ stent during the mechanical thrombectomy for recanalization of acute Ischemic stroke: lessons learned from the removal of stent via surgical embolectomy. J Korean Neurosurg Soc. 2013;53:360-3.

11. Gascou G, Lobotesis K, Machi P, Maldonado I, Vendrell JF, Riquelme C, Eker O, Mercier G, Mourand I, Arquizan C, Bonafé A, Costalat V. Stent retrievers in acute ischemic stroke: complications and failures during the perioperative period. AJNR Am J Neuroradiol. 2014;35:734-40.

12. Kim ST, Jin SC, Jeong HW, Seo JH, Ha SY, Pyun HW. Unexpected detachment of Solitaire Stents during mechanical thrombectomy. J Korean Neurosurg Soc. 2014;56:463-8.

13. Lee SY, Youn SW, Kim HK, Do YR. Inadvertent detachment of a retrievable Intracranial stent: review of manufacturer and user facility device experience. Neuroradiol J. 2015;28:172-6.

14. Akpinar S, Yilmaz G. Spontaneous Solitaire ${ }^{\mathrm{TM}}$ AB thrombectomy stent detachment during stroke treatment. Cardiovasc Intervent Radiol. 2015;38:475-8.

15. Castaño C, Dorado L, Remollo S, García-Bermejo P, Gomis M, Pérez de la Ossa N, Millán M, García-Sort MR, Hidalgo C, LópezCancio E, Cubells C, Dávalos A. Unwanted detachment of the Solitaire device during mechanical thrombectomy in acute ischemic stroke. J Neurointerv Surg. 2016;8:1226-30.

16. Parthasarathy R, Gupta V, Goel G, Mahajan A. Solitaire stentectomy: 'deploy and engage' and 'loop and snare' techniques. J Neurointerv Surg. 2018;10:e6-e6.

17. Kinariwala JP, Rajah GB, Luqman AW. Retained Solitaire FR device after mechanical thrombectomy: Case review and management strategies. Brain Circ. 2018;4:185-7.

18. Kung DK, Abel TJ, Madhavan KH, Dalyai RT, Dlouhy BJ, Liu W, Jabbour PM, Hasan DM. Treatment of endovascular coil and stent migration using the merci retriever: report of three cases. Case Rep Med. 2012;2012:1-7.

19. Schechter MA, O'Brien PJ, Cox MW. Retrieval of iatrogenic intravascular foreign bodies. J Vasc Surg. 2013;57:276-81.

20. Miley JT, Rodriguez GJ, Tummala RP. Endovascular retrieval of a prematurely deployed covered stent. World J Radiol. 2015;7: $139-42$.

21. Barburoglu M, Aydin K. Rescue retrieval of a fully deployed lowprofile Intracranial stent after acute occlusion. World Neurosurg. 2016;85:349-52.

22. Meyer T, Nikoubashman O, Kabelitz L, Müller M, Othman A, Afat S, Kramer M, Wiesmann M, Brockmann MA, Brockmann C. Endovascular stentectomy using the snare over stent-retriever (SOS) technique: An experimental feasibility study. PLoS ONE. 2017;12:e178197.

23. Simgen A, Tomori T, Mühl-Benninghaus R, Bomberg H, Yilmaz U, Körner H, Laschke MW, Menger MD, Reith W. Retrieval of migrated volume coils using different clot retrievers in a porcine model. Clin Neuroradiol. 2018;28:593-600.

24. Simgen A, Ley D, Roth C, Cattaneo GF, Mühl-Benninghaus R, Müller A, Körner H, Kim YJ, Scheller B, Reith W, Yilmaz U. Evaluation of occurring complications after flow diverter treatment of elastase-induced aneurysm in rabbits using micro-CT and MRI at 9.4T. Neuroradiology. 2016;58:987-96.

25. Kabbasch C, Mpotsaris A, Chang DH, Hiß S, Dorn F, Behme D, Onur O, Liebig T. Mechanical thrombectomy with the Trevo ProVue device in ischemic stroke patients: does improved visibility translate into a clinical benefit? J Neurointerv Surg. 2016;8:778-82.

26. Mpotsaris A, Bussmeyer M, Weber W. Mechanical thrombectomy with the penumbra $3 \mathrm{D}$ separator and lesional aspiration: technical feasibility and clinical outcome. Clin Neuroradiol. 2014;24:245-50. 
27. Kabbasch C, Mpotsaris A, Liebig T, Söderman M, Holtmannspötter M, Cronqvist M, Thornton J, Mendes Pereira V, Andersson T. Firstin-man procedural experience with the novel Embotrap ${ }^{\circledR}$ revascularization device for the treatment of ischemic stroke-A European multicenter series. Clin Neuroradiol. 2016;26:221-8.

28. O'Hare AM, Rogopoulos AM, Stracke PC, Chapot RG. Retrieval of displaced coil using a Solitaire ${ }^{\circledR}$ stent. Clin Neuroradiol. 2010;20:251-4.

29. Nikoubashman O, Pjontek R, Brockmann M-A, Tolba R, Wiesmann $M$. Retrieval of migrated coils with stent retrievers: an animal study. AJNR Am J Neuroradiol. 2015;36:1162-6.

30. Masoud H, Nguyen TN, Martin CO, Holloway WE, Ambekar S, Yavagal DR, Haussen DC, Nogueira R, Lozano DJ, Puri A, Quateen A, Iancu D, Abraham MG, Chen M, Mehta S, Malisch T, Marden F, Novakovic R, Roy D, Weill A, Norbash AM. Inadvertent stent retriever detachment: a multicenter case series and review of device experience FDA reports. Intervent Neurol. 2016;4:75-82.

31. Kwon HJ, Chueh JY, Puri AS, Koh HS. Early detachment of the Solitaire stent during thrombectomy retrieval: an in vitro investigation. J Neurointerv Surg. 2015;7:114-7.

32. Runck F, Maurer CJ, Berlis A. Complication rates using CASPER dual-layer stents for carotid artery stenting in acute stroke : a 3-year single center experience. Clin Neuroradiol. 2019;387:1723-7.

33. Chapot R, Stracke P, Nordmeyer H. Stentectomy: retrieval of stents after stent assisted coiling. Interv Neuroradiol. 2015;21:160.

34. Sandmann J, Müschenich FS, Riabikin A, Kramer M, Wiesmann M, Nikoubashman O. Can silicone models replace animal models in hands-on training for endovascular stroke therapy? Interv Neuroradiol. 2019;25:397-402. 